\title{
Exclusividad y exclusión junto al agua. Reflexiones sobre el urbanismo neoliberal en Corrientes, Argentina
}

Rus, María Florencia

Arquitecta. Magíster en Urbanismo por la Universidad Nacional de Córdoba. Becaria doctoral CONICET-UNNE, en Instituto de Investigación y Desarrollo en Vivienda (IIDVi-UNNE) e Instituto de Investigaciones para el Desarrollo Territorial y Hábitat Humano (IIDTHH, CONICET-UNNE).

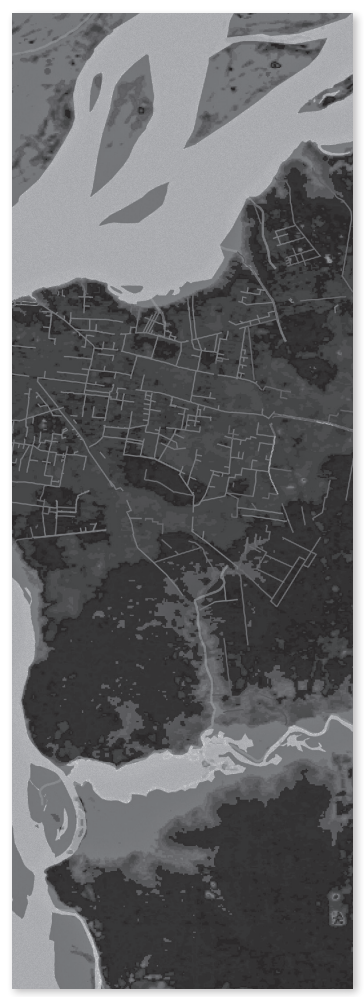

http://dx.doi.org/10.30972/crn.31315781 


\section{Exclusividad y exclusión junto al agua. Reflexiones sobre el urbanismo neoliberal en Corrientes, Argentina}

\section{Resumen}

En este artículo se busca introducir, describir e interpretar los procesos de transformación territorial que se han manifestado en los últimos años en Corrientes, Argentina. Las políticas y prácticas ensayadas poseen una racionalidad neoliberal en la que participan agentes que conducen a la privatización de ecosistemas como los humedales, la producción de espacios y productos inmobiliarios de segmento social exclusivo, el destrabe de tierra pública para negocios inmobiliarios, la expulsión de quienes ocupan informalmente para construir su hábitat, entre otras consecuencias. Las cartografías de la desigualdad, lejos de tener una raíz reciente, se vinculan con transformaciones históricas que se contemplarán en el trabajo para pensar en el devenir de las políticas territoriales actuales. Se enmarca en una investigación exploratoria que busca describir cómo las políticas urbanas de raigambre neoliberal contribuyen a la producción de mayores desigualdades, la acumulación de riquezas y la socialización de costos ambientales.

\section{Palabras clave}

Urbanismo neoliberal; humedales; desigualdad; privatización; conflicto.

\section{Exclusivity and exclusion next to water. Reflections on neoliberal urbanism in Corrientes, Argentina}

\section{Abstract}

This article seeks to introduce, describe and interpret the processes of territorial transformation that have manifested in recent years in Corrientes, Argentina. The policies and practices tested possess a neoliberal rationality in which different agents are involved that lead to the privatization of ecosystems such as wetlands, the production of spaces and real estate products of exclusive social segment, the unlocking of public land for real estate businesses, the expulsion of those who occupy informally to build their habitat, among others consequences. The cartographies of inequality, far from having a recent root, are linked to historical transformations that will be contemplated in the work to think about the future of current territorial policies. It is part of an exploratory research that seeks to describe how neoliberal urban policies contribute to the production of greater inequalities, the accumulation of wealth and the socialization of environmental costs.

\section{Keywords}

Neoliberal urbanism; wetlands; inequality; privatization; conflict.

\section{Exclusividade e exclusão junto à água. Reflexões sobre o urbanismo neoliberal em Corrientes, Argentina}

\section{Resumo}

Neste artigo procura-se introduzir, descrever e interpretar os processos de transformação territorial que se manifestaram nos últimos anos em Corrientes, Argentina. As políticas e práticas testadas possuem uma racionalidade neoliberal na qual participam agentes que conduzem à privatização de ecossistemas como as zonas húmidas, a produção de espaços e produtos imobiliários de segmento social exclusivo, o desbloqueio de terras públicas para negócios imobiliários, a expulsão de quantos ocupam informalmente para construir o seu habitat, entre outras. As cartografias da desigualdade, longe de ter uma raiz recente, vinculam-se a transformações históricas que serão contempladas no trabalho para pensar no devir das políticas territoriais atuais. Enquadra-se numa investigação exploratória que procura descrever como as políticas urbanas de tradição neoliberal contribuem para a produção de maiores desigualdades, a acumulação de riquezas e a socialização de custos ambientais.

\section{Palavras-chave}

Urbanismo neoliberal; zonas húmidas; desigualdade; privatização; disputa. 


\section{Introducción}

Desde los márgenes de la producción académica y desde una ciudad intermedia argentina, Corrientes, se abordan en este trabajo las estrategias de gobierno neoliberal cristalizadas en transformaciones urbanas que se dieron desde comienzos de siglo. Por tal razón, en este trabajo se busca introducir, describir e interpretar los procesos de transformación y las formas particulares de habitación, valorización, producción y apropiación de áreas marcadas por la presencia del agua.

Este trabajo se sustenta en aproximaciones construidas en el marco de una investigación en la cual se considera que en los últimos años se intensificó la división social y clasista del espacio, lo que permitió la acumulación de beneficios y riquezas a partir de la producción de enclaves de extrema disparidad en las condiciones de reproducción de la vida en la ciudad. Lejos de poder disociarse, detrás de estas configuraciones existen políticas y prácticas sustentadas por una marcada racionalidad neoliberal, orientadas por justificaciones políticas sobre el deber ser de la agenda territorial. La preocupación radica en que a partir del siglo XX se han reafirmado dinámicas de privatización de ecosistemas como los humedales, la producción de productos inmobiliarios de segmento social exclusivo, la expulsión de quienes ocupan informalmente para construir su hábitat o la exclusión de áreas que quedan por fuera del centro. El mapa de la desigualdad no es reciente, se vincula con dinámicas históricas que se contemplarán en el trabajo para pensar en el devenir de la agenda territorial del gobierno actual.

En cuanto a la metodología utilizada, se trata de una investigación exploratoria basada en el abordaje cualitativo de casos, que son presentados brevemente en este trabajo, pero puestos en relación para reflexionar sobre el carácter específico de los procesos territoriales locales. Para esto fueron revisadas fuentes diversas, como notas de prensa, registros de campo, informes de organismos públicos y documentación oficial.

El “urbanismo neoliberal” es una noción amplia y polisémica retomada por diferentes autores provenientes tanto de países del llamado "norte global”, que indagan sobre las políticas y transformaciones espaciales del neoliberalismo, AALBERS (2013); BRENNER ET AL. (2009); HARVEY (2008); SмIтH (2005), como del sur, en múltiples trabajos como el de RolniK (2017); Pintos Y Narodowsky (2012); Svampa y Viale (2016); estudios compilados en Vázquez Duplat (2017); SocoLOFF ET AL. (2020). Esta se ha constituido en una corriente y matriz para pensar la producción 
1. Hablamos de políticas de liberalización, desregulación de diferentes mercados, privatización, despolitización, monetarismo, etc. (MUDGE, 2008).

2. Refiere al sentido común que promueven las élites sobre otros que habitan la ciudad, las responsabilidades o lugares que ocupan diferentes sujetos, la orientación a constituir redes o coaliciones de intereses convergentes

(PINTOS \& NARODOWSKY, 2016) más o menos duraderas con empresas inmobiliarias, desarrolladoras, financieras, antes que sindicatos, organizaciones sociales, ambientales o ciudadanas (MUDGE, 2008). o reestructuración de los órdenes y desigualdades espaciales de nuestras ciudades a partir de las transformaciones y expansiones del mercado inmobiliario-financiero, sus formas de fijación y desposesión en la ciudad y los conflictos urbanos derivados.

En general, el neoliberalismo puede ser comprendido desde sus diferentes rostros: como un despliegue de ideas que surgen de centros de producción académica (anglosajones o norteamericanos) y que se constituyen en un proyecto intelectual; como un repertorio de políticas estatales o reformas necesarias de promover ${ }^{1}$ y/o como una forma particular de hacer política $^{2}$ desde los años 70 y con mayor énfasis desde los años 90 (MudGE, 2008). Sin embargo, desde los estudios de gubernamentalidad inspirados por Foucault (2007), el neoliberalismo es entendido como una forma de ejercicio del gobierno en la cual se pone en práctica un conjunto de tecnologías para la conducción de la población. En este sentido, ciertas racionalidades se han arraigado en nuestras prácticas cotidianas, como es el caso de la incorporación de la lógica empresarial "managerial" a diferentes ámbitos. El caso paradigmático es el del Estado, focalizado cada vez más en propuestas de "modernización”, organización laboral basada en el mérito, la flexibilización o el ejercicio del gobierno "a través" del mercado, es decir, como "cataliza[do]r de las ofertas del sector privado" (BoticelLi, 2017, p. 687). La gubernamentalidad neoliberal y financiera percibe a los individuos como homo economicus, sujetos libres y empresarios de sí mismos, propone una naturalización de la desigualdad, la cual posibilita la competencia de hombres libres en el mercado (HARVEY, 2008). Este lugar posiciona a los sujetos e instituciones de gobierno mirando hacia una totalidad transaccional llamada "sociedad civil", la cual se debe coordinar, posibilitar, disciplinar (Foucault, 2007), para lograr como objetivo último garantizar la libertad económica y defender las reglas del derecho que consoliden la propiedad privada absoluta (RoLnIK, 2017). Por otra parte, quienes en nuestras ciudades latinoamericanas son incapaces de satisfacer necesidades básicas (alimento, habitación, educación) y mucho menos competir para participar de ciertas redes sociotécnicas son culpabilizados, criminalizados por su condición o proporcionados de subsidios a cuentagotas para la reconstrucción ética (RosE, 1997).

Lejos de reconocerse esta proclamada utopía igualitaria o de mercados libres, "el terreno de la acción se afianza en una arena de operaciones políticas que intermedian para la concreción de sus fines” (Pintos \& NARoDowsky, 2012, p. 24), donde los críticos de la presunción apolítica neoliberal cada vez más presente reconocen el "carácter políticamente construido de todas las relaciones económicas” (BRENNER ET AL., 2009, p. 4). Es por esto que en este 
trabajo no se busca hacer una extrapolación acrítica de las reflexiones de estos autores, sino que más bien se indaga en aquellas iniciativas privadas que han incidido fuertemente en la conformación del territorio y aquellas que adquieren el carácter de políticas públicas. Estas son generalmente justificadas a partir de la retórica de la escasez (de dinero, recursos, presupuestos) (Foucault, 2007) y alegando las oportunidades de inversión, la apertura al turismo, la generación de empleo o las promesas de desarrollo.

En este sentido, la sacralidad del mercado ha permitido que en este siglo se afiance el avance del capital inmobiliario-financiero, con un conjunto de "inversores especializados" que conciben la vivienda y el suelo urbano como un activo o asset class (Socoloff Et AL., 2020) utilizado para captar y reservar valor, tanto como "fijar" capital excedente (RoLNIK, 2017, p. 26). Esta dinámica de mercantilización de la tierra y vivienda extensiva y recurrente excluye a grandes sectores populares y medios y se constituye en una enorme barrera para el cumplimiento de derechos básicos (Rodríguez \& Socoloff, 2017). Siguiendo esto, es frecuente que aquellos que ocupan lugares en el Estado se vuelvan agentes garantes de la fijación de capital en el territorio proveyendo marcos jurídicos e institucionales que los posibilitan o legitiman, trasladando riesgo a sectores populares, subsidiando su demanda, velando por el absolutismo de la propiedad privada, desregulando el mercado inmobiliario y posibilitando valoraciones excepcionales, etc.

El marco conceptual interpretativo de este trabajo parte de estos abordajes estructuralistas y postestructuralistas y busca rastrear "las contradictorias y crónicamente inestables geografías del neoliberalismo realmente existente” (BRENNER ET AL., 2009, p. 3) en ciudades como Corrientes y reconocer su trayectoria. Por otro lado, resultan centrales los aportes del campo de la ecología política latinoamericana, la cual proclama que la producción de un modelo de ciudad excluyente en este contexto no puede separarse de las formas de insustentabilidad o degradación ambiental diferencialmente sufridas. Partiendo de una crítica al modelo de desarrollo que promueve el neoliberalismo, vinculado con formas de colonización y el ideal modernizador que sostiene el crecimiento económico ilimitado, Svampa Y VIALE (2014) construyen una posición local contrahegemónica que cuestiona la destitución de otras formas de valorización y la producción de daños irreversibles y sistemáticos en los ecosistemas. Se sustentan en las resistencias que emanan desde el territorio, el denominado "giro ecoterritorial de las luchas" (Svampa \& Viale, 2014, p. 21). A esto se suma la centralidad de comprender el territorio y la presencia del agua en abundancia (ríos, esteros, lagunas, 
3. Según el INDEC EPH (primer trimestre de 2019), la ciudad de Corrientes posee un total de 375.733 habitantes.

4. Existen un 40,9\% de personas pobres y $11,8 \%$ indigentes en la ciudad de Corrientes, según la EPH (primer semestre de 2020, INDEC), lo que se traduce en 156.000 personas pobres $y$ 44.655 indigentes.

5. El río Paraná, en el sector del "Paraná medio", puede variar de $17.000 \mathrm{~m}^{3} / \mathrm{s}$ a $60.000 \mathrm{~m}^{3} / \mathrm{s}$. (DI PaOLI, 2004, en ALCALÁ \& RUS, 2017).

6. Corresponde a la llanura Chaqueña y la Mesopotamia.

7. Las precipitaciones en las cuencas superiores se concentran, por lo general, en el período estival y a principios de otoño, y originan crecidas en los meses de febrero y marzo en la cuenca media.

8. Plano hipsométrico que refleja cotas de riesgo hídrico (por anegamiento y crecida de ríos), elaborado mediante modelo digital de terreno en formato ráster (resolución espacial de 30 $m$ ). Este fue suministrado por la Comisión Nacional de Actividades Espaciales (CONAE), en el que se definieron cotas de inundación y anegamiento a partir de lo establecido en MC (2014). bañados, acuíferos) como parte de complejos ecosistemas de humedales con sus ciclos hidromorfológicos. Estos son inseparables de las prácticas sociales históricas, y es necesario comprender sus hibridaciones (ReygadAs, 2018; MARTín \& LARSIMONT, 2016).

Para relacionar estos temas y entender los procesos territoriales de Corrientes, el trabajo fue organizado en tres partes: en un primer momento, a partir de la construcción de cartografías y el uso de fuentes secundarias, se contextualiza la ciudad reflexionando sobre sus procesos de transformación previos, la herencia de una estructura patrimonial concentrada y la presencia de ciclos hídricos dependientes del caudal de lluvias o de las dinámicas del río Paraná; en un segundo momento, se describen las prácticas sistemáticas que han acontecido en el territorio en las últimas décadas: el avance hacia la periferia de un segmento social exclusivo, la marginalización de grandes grupos en las costas sometidos a dinámicas de exclusión total (desde inobservancia hasta desalojos), y se exponen brevemente procesos de destrabe de suelo para el ingreso de capital inmobiliario-financiero. Por último, se ensayan algunas reflexiones sobre esta agenda de gobierno neoliberal instituida y en avance.

\section{El territorio heredado}

Corrientes $^{3}$ es una ciudad intermedia del nordeste argentino, capital provincial fundada en la época colonial por el avance español en su estrategia colonizadora, imperialista y extractivista, que se sustentó en diversas técnicas de apropiación del territorio y disciplinamiento de los habitantes originarios. Se trata de una de las áreas urbanas más pobres del país ${ }^{4}$, y forma parte de un conjunto de centros urbanos de la región sudamericana conocida como la Cuenca del Plata. En esta, son características las crecientes periódicas y extraordinarias de los ríos ${ }^{5}$, como el río Paraná, en torno al cual se funda Corrientes. A su vez, la región posee regímenes pluviales de clima subtropical (1000 a $1500 \mathrm{~mm}$ anuales) y una topografía de llanura ${ }^{6}$ con pendientes mínimas. El área de estudio se ubica en la región del Paraná Medio y se encuentra determinada por ciclos hídricos ${ }^{7}$ que varían entre crecidas y momentos de estiaje (SNAIDER \& RAmírez, 2018) y por el agua que escurre en el territorio, a partir de las lluvias y las posibilidades de drenaje.

El territorio abordado es presentado sintéticamente en los mapas 1 y $2^{8}$ (ver páginas 118 y 119), donde se puede observar que las costas poseen un perfil topográfico que combina zonas de barrancas, tramos defendidos por obras de infraestructura (defensas o paseos 
costeros) o ecosistemas de bañados al norte y al sur; estos últimos dependen de los ciclos de inundación o estiaje. Por otro lado, hacia el este del territorio se distribuyen lagunas sobre lomadas arenosas y esteros, un ecosistema de gran complejidad que atraviesa el norte de la provincia (CONTRERAS \& OJEDA, 2018) y que tiene su pendiente hacia la zona sur de la ciudad de Corrientes.

Si bien en las áreas ribereñas históricamente se han consolidado los barrios populares, entre mediados y fines del siglo XX se avanzó en la planificación y configuración de una costa central guiada por preceptos modernizadores y numerosas inversiones públicas. El proceso detrás de esas materializaciones ha sido recientemente estudiado desde una perspectiva histórica crítica para pensar el proceso conflictivo invisibilizado (Rus, 2019b). Este abordaje permite comprender las trayectorias de estas transformaciones y la participación cada vez mayor en nuestros tiempos de agentes inmobiliarios, empresariales y de gobierno en el acaparamiento, la privatización, el moldeamiento de áreas cercanas al agua (Rus, 2019a; Rus, 2019b) para capitalizar rentas de monopolio de segregación (JARAMILLo, 2008), o la extracción de una renta natural por la explotación de bienes comunes (PINTOS \& NARoDowsky, 2012). No obstante, en el avance fragmentado sobre estos territorios se desconoce el impacto ambiental global que se produce al disminuir los servicios ecosistémicos para mitigar las inundaciones. En este sentido, tal y como se aborda en Alcalá y Rus (2018), se puede ver una histórica alternancia entre ciclos húmedos, cuando se ensayan y se invierte desde el Estado en obras estructurales o no estructurales, mientras que en algunas áreas se sufre en los cuerpos las inundaciones y anegamientos; y ciclos secos, en los que avanza la ocupación, urbanización y privatización de espacios del agua.

El área comprendida como el Gran Corrientes está conformada por las localidades de Corrientes Capital, Riachuelo y Santa Ana. La capital ha tenido un crecimiento exponencial de población a partir de los años 50 (FoschiatTi \& Bolsi, 1993), y a partir de los 90 un proceso de movilidad residencial hacia localidades próximas, que produjo una relación metropolitana de "expansión dispersa" o "incipiente" (AlberTo et Al. , 2018). A su vez, a partir de los 90 existe una tendencia a mayor extensión de la mancha urbana en relación con el aumento de población, que implica formas de dispersión ${ }^{9}$ (tabla 1; ver p. 124, y mapa 3; ver p. 122).

Por otro lado, si bien la desigualdad urbana siempre es estudiada como producto reciente, en Rus (2019b) se indaga cómo esta tiene sus raíces en procesos históricos que son naturalizados
9. Según las estimaciones realizadas en la tabla 1 , el aumento poblacional entre 2010 y 2021 es de un $25,28 \%$, mientras que el crecimiento poblacional es de un $44,8 \%$. Por lo tanto, se puede ver un proceso de dispersión de un $20 \%$. 


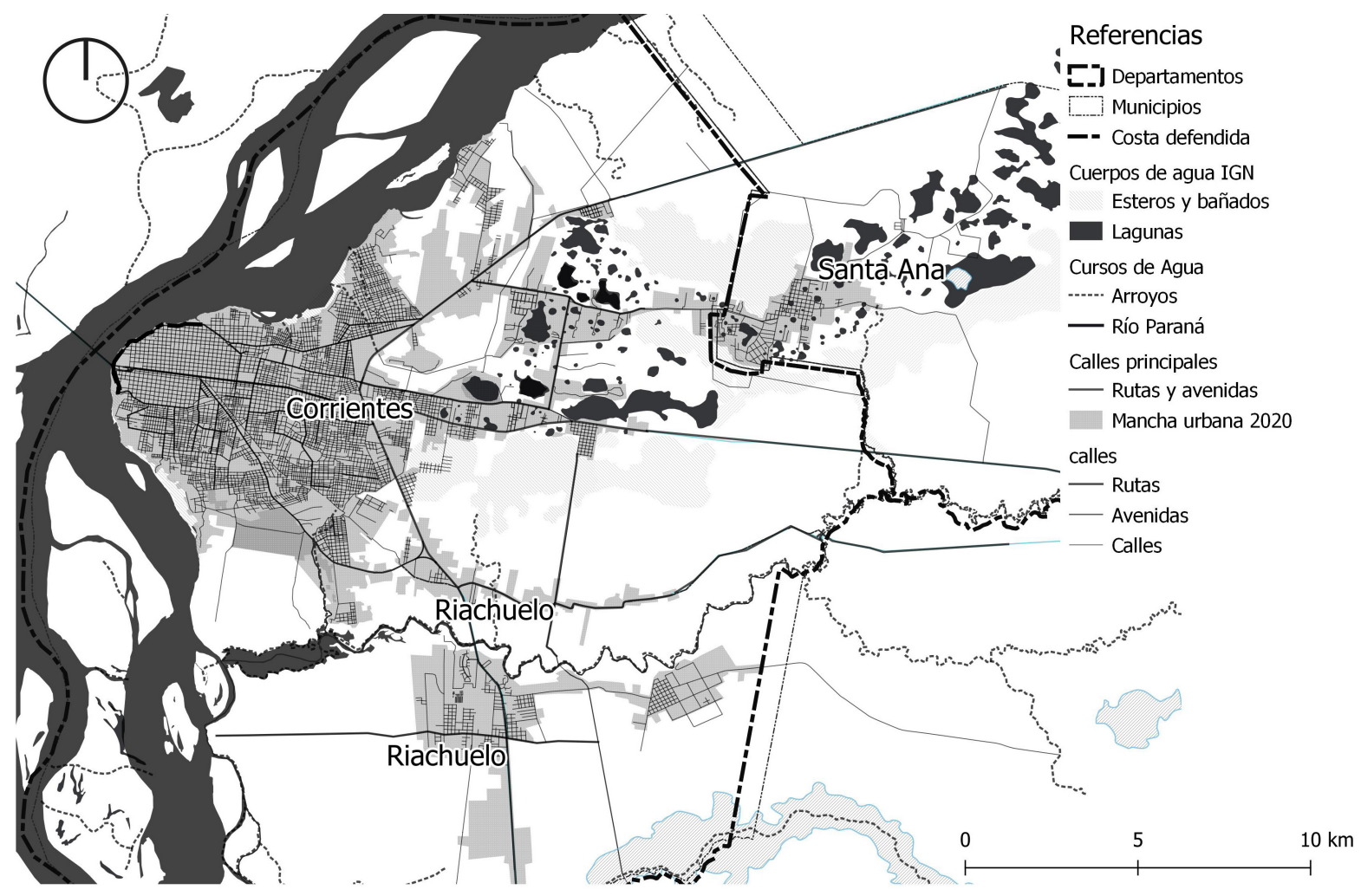

Mapa 1. Hidrografía y mancha urbana del Área Metropolitana de Corrientes. Fuente: elaboración propia sobre la base de recursos de: OSM, IGN Y Municipalidad de Corrientes (MC); 2020 en el presente, como por ejemplo el acaparamiento de medios productivos como la tierra y el agua o la expulsión social de grupos marginales no-propietarios del campo o de áreas urbanas. La desigualdad existente hoy llama a componer una estrategia, y esta debe estructurarse sobre la base de una interpretación de la historia. Así pues, en Corrientes, a partir de los años 50 se reorganiza aquello que desde el siglo XIX implicó el proceso de concentración de riqueza y acaparamiento de la tierra rural en unas pocas manos. Se trató de un largo período de expulsión de población hacia la capital (más de un 40 \%). La ciudad, según 


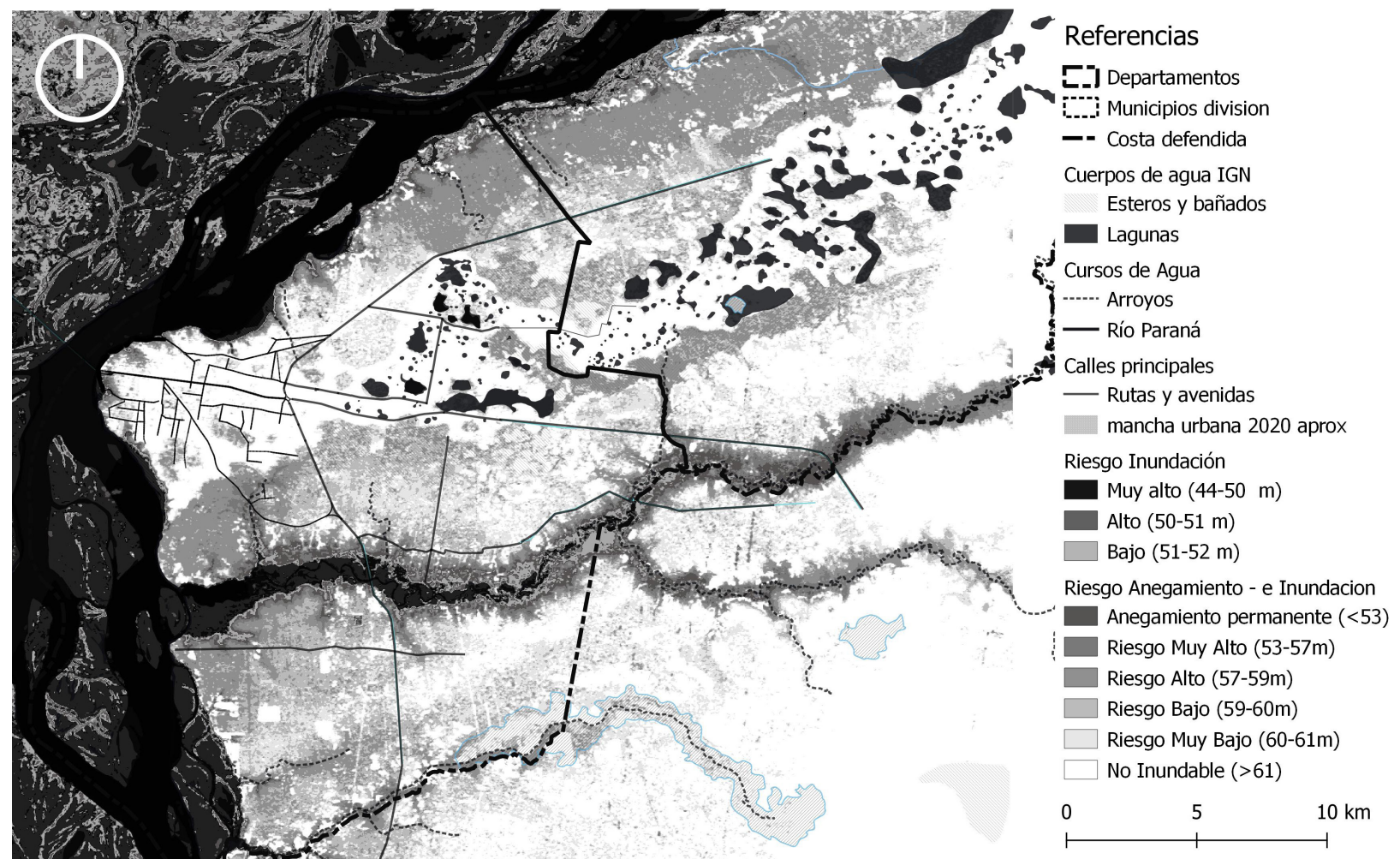

Foschiatti y Bolsi (1993), no contaba con los servicios o la capacidad de empleo para absorber las necesidades de estos grupos. A su vez, la demanda de suelo se enfrentó con una estructura de propietarios de importantes hectáreas en todo el departamento, pero sobre todo en el entorno inmediato del área que se definía como urbana (determinada por la zanja perimetral), donde la propiedad estaba concentrada por las élites, actores partícipes del gobierno local o provincial, de familias patricias y la clase burguesa. Así, para 1988 un tercio de los hogares censados en la ciudad tenían necesidades básicas insatisfechas.
Mapa 2. Plano hipsométrico sobre la base de cotas de riesgo hídrico $e$ infraestructura pluvial. Fuente: elaboración propia sobre la base de Modelo Digital del Terreno provisto por CONAE y SIG MC, 2020 
10. La práctica de entubamiento para producir vialidades es hoy muy cuestionada por condicionar el caudal de escurrimiento, ser proclives al taponamiento, dificiles de mantener, se invisibilizan conexiones clandestinas, etc.
Es sabido que la perpetuación del capitalismo depende del acaparamiento de clase de los medios de producción, entre otros mecanismos, para la explotación y alienación de otros. Así también, como en la mayor parte de Occidente, el parcelario catastral se constituyó en un dispositivo de dominación desplegado sobre el territorio y abstraído de los ecosistemas o formas de vida existentes. Corrientes se originó entre diferentes arroyos que desembocaban en el río Paraná (mapa 2). Estos fueron observados por el discurso y mandato modernizador como espacios insalubres, obstáculos que salvar para el embellecimiento y el avance de la urbanización.

El Liberal, medio de comunicación de gran impacto en el período, publicó algunas notas periodísticas al respecto que fueron recopiladas por Minadeo (1988). En estas se refería al entubamiento del arroyo Poncho Verde como una obra que "anula el foco infeccioso más grande de la ciudad, haciendo desaparecer el peligro de epidemias y enfermedades que significa, y permitiendo el hermoseamiento de la ciudad al ganar para la urbanización de ella una vasta zona de terrenos" (El liberal, 8 de agosto de 1955). Como se relata, a mediados del siglo XX se avanzó en el entubamiento de arroyos del área central, como Isiró, Salamanca, Manantiales, Poncho Verde, Limita; sin embargo, aún subsisten por debajo de las calles, funcionando como desagües pluviales de la ciudad, que muchas veces desbordan ante la falta de mantenimiento o caudales mayores que los calculados ${ }^{10}$.

Por otro lado, alrededor de estos arroyos y en torno de la costa se han localizado entre mediados del siglo XIX y principios del XX los barrios populares, como es el caso del Tacurú o Camba Cuá, junto al arroyo Salamanca y el Poncho Verde. Conforme la construcción de obras de defensas costeras, como la Costanera General San Martín, el puerto, las obras de entubamiento, el avance del pavimento y la infraestructura de saneamiento, se produjo un proceso de valorización paulatina del suelo, la ocupación de sectores de mayores ingresos y el consecuente desplazamiento de la pobreza. En Rus (2019b) se puede hacer un seguimiento más detallado de estos procesos y el conjunto de dispositivos (proyectos, ordenanzas, disposiciones, discursos) que consolidaron a los barrios La Rosada, Libertad, Camba Cuá como los más valorizados por el mercado inmobiliario, con un paulatino recambio de viviendas unifamiliares por torres para vivir, alquilar o invertir a partir de los años 90. En los 70, cuando se construye el Puente Interprovincial Gral. Belgrano, se 
desplaza la antigua estación de trenes y se impulsa la consolidación de la avenida 3 de Abril, el avance del pavimento y el completamiento de la infraestructura. El área central quedó definida entre las "cuatro avenidas" (San Martín, 3 de Abril, Poncho Verde, Artigas), hoy una de las áreas más valorizadas y cualificadas de la ciudad ${ }^{11}$ (Atlas ID, 2014; en Rus, 2019b).

Por otra parte, el territorio de bañados, arroyos y barrancas junto al río por fuera de este centro fue donde se organizaron los asentamientos, destino de las masas populares que trabajan sobre la base de la pesca artesanal, ladrilleras, pequeños astilleros o industrias madereras (Rus, 2019b). Es así que en los espacios junto al río existen en la actualidad condiciones de vida diametralmente dispares entre aquellos tramos defendidos por obras de infraestructura: la Costanera Gral. San Martín (1929-1944), el puerto y, más recientemente, la Costanera Juan Pablo II (1998-2008) y el resto de las áreas ribereñas. Esta comparación puede verse en el mapa 4, que expone una categorización de formas de producción del suelo urbano basada en AlCALÁ y Rus (2018). Los barrios populares han crecido hacia los bordes de los arroyos o zanjas (mapas 2 y 4) y hacia otros bordes periurbanos o límites; levantados mediante la autogestión y autoconstrucción de sus pobladores; y expuestos a condiciones de déficit urbano, vulnerabilidad hídrica, dificultades de acceso al empleo, a la salud, a la justicia (Alcalá y Rus, 2017). Sin embargo, estas otras costas al margen, múltiples y heterogéneas, donde habita un gran porcentaje de los ciudadanos de la ciudad, han sido objeto de reivindicaciones constantes de organizaciones y asambleas barriales. A pesar de esto, fueron históricamente ignoradas por las gestiones u obtienen respuestas irrisorias. Aunque resulte casi inobjetable que debieran pensarse como áreas prioritarias para orientar políticas de mejoramiento urbano o barrial, parecen ocupar el último lugar en una agenda encabezada por el área central.

Por otro lado, hacia el este y sur se fueron ocupando áreas bajas y anegadizas, en gran parte desde los 70 en adelante, por el juego entre las operatorias estatales de viviendas, las empresas constructoras, las estructuras de propiedad que se consolidaron históricamente y los loteos privados que avanzaron sobre el territorio (GutiérRez \& SÁnchez NeGretTe, 1988). En este proceso de urbanización hacia el sur se ocuparon los grandes bajos o lagunas donde ahora se localizan barrios con condiciones de anegamiento, como por ejemplo Laguna Brava y La Olla.
11. Esta información se conoce a partir de los estudios presentados en la Plataforma Atlas ID de la Subsecretaría de Planificación Territorial de la Inversión Pública a partir del año 2004. 
12. La aproximación a las manchas urbanas fue elaborada utilizando como base los recursos proporcionados por Atlas ID y a partir de la fotointerpretación de imágenes satelitales históricas.

\section{Referencias}

ᄃ-J Departamentos

Municipios

-- Costa defendida

Cuerpos de agua IGN Esteros y bañados

Lagunas

Cursos de Agua

-.-.-. Arroyos

\section{— Río Paraná}

Calles principales

— Rutas y avenidas calles

\section{— Rutas \\ - Avenidas \\ - Calles}

Mancha urbana 1991

Mancha Urbana 2010

Mancha urbana 2020

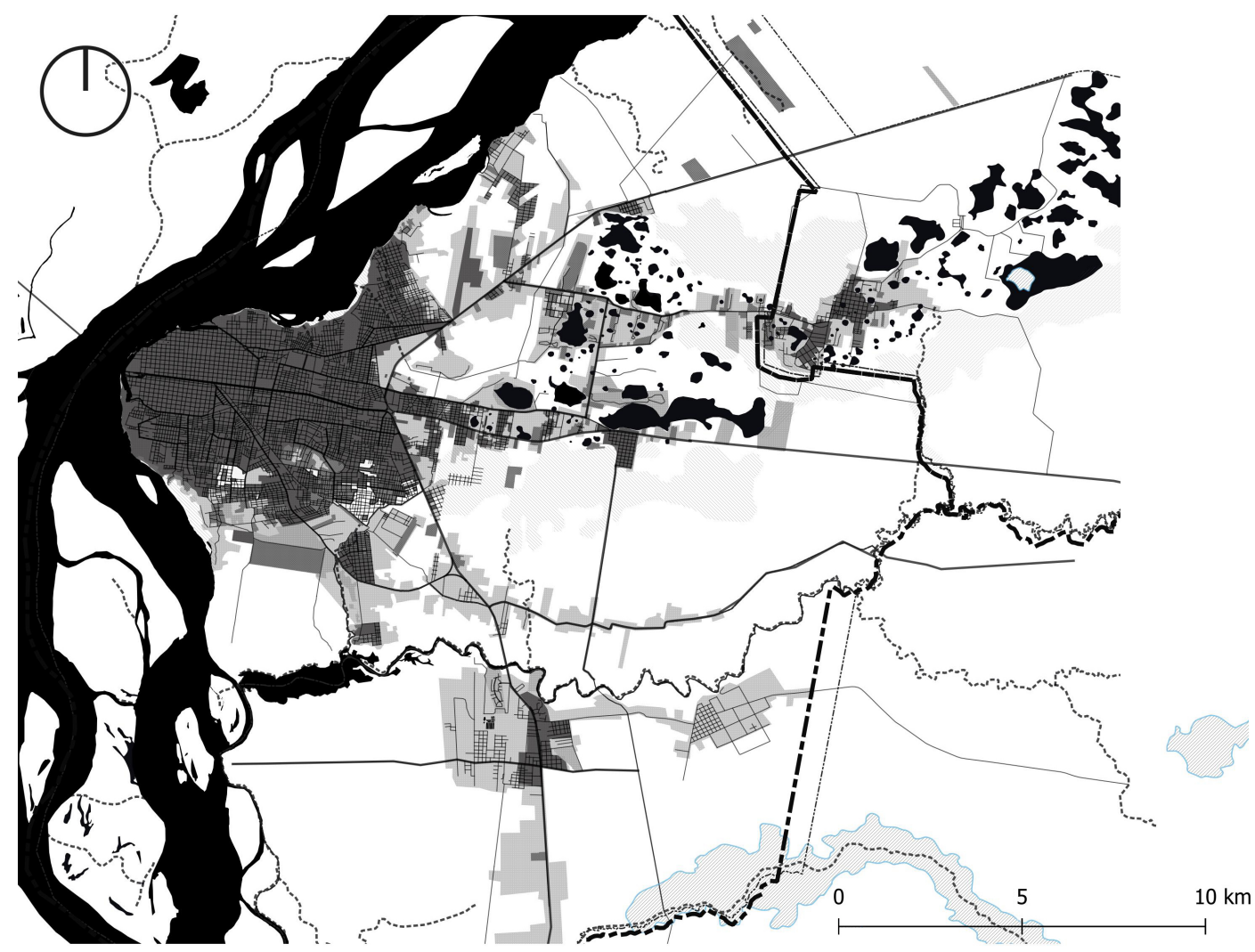

Mapa 3. Comparación de manchas urbanas de 1999, 2010, 2021. Fuente: elaboración propia ${ }^{12}$ sobre la base de recursos de Atlas ID, MC, IGN, OSM; 2021 


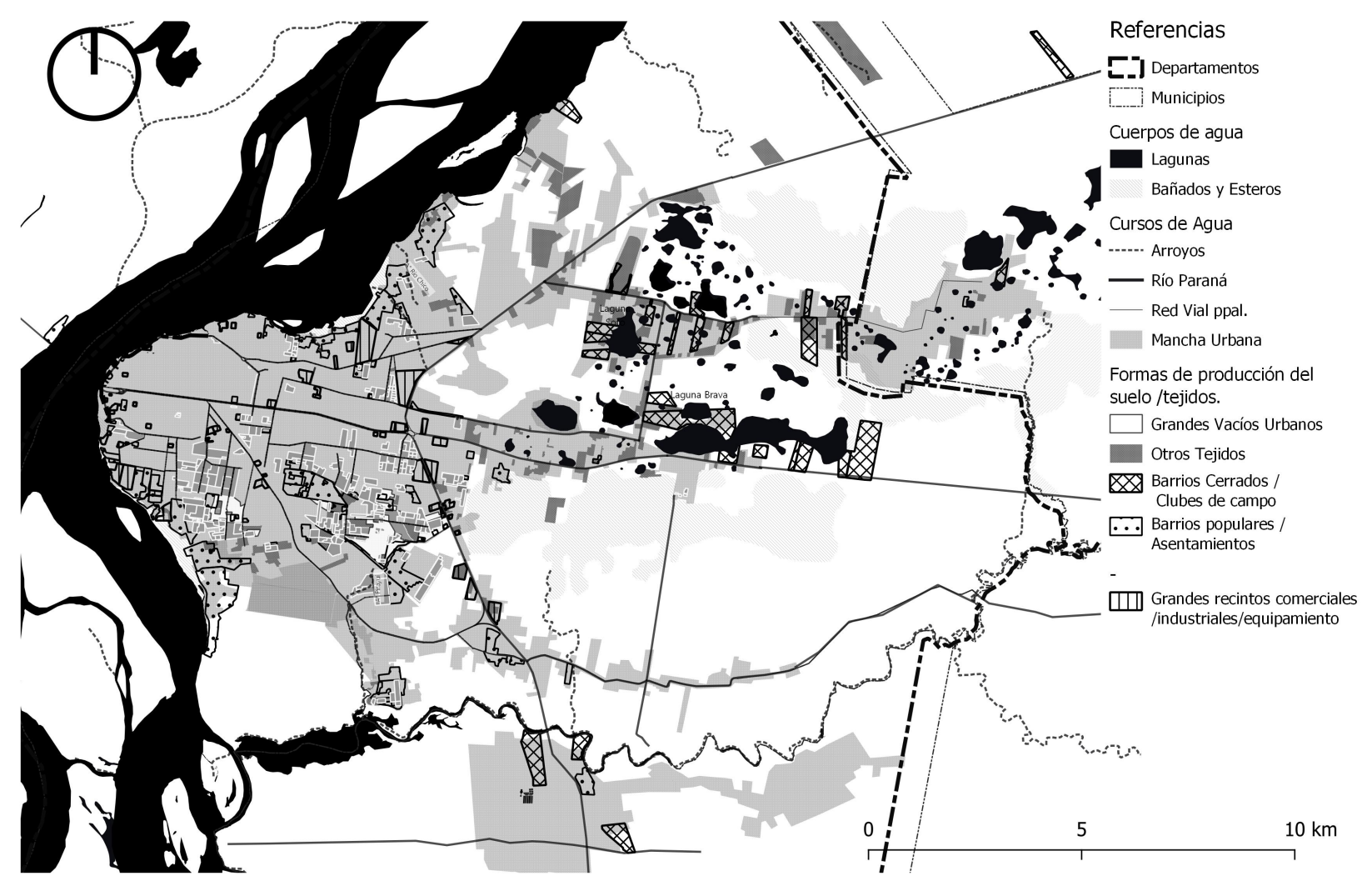

Mapa 4. Algunos tejidos y formas de producción del suelo urbano. Fuente: elaboración propia sobre la base de recursos de Atlas ID, MC, IGN, OSM; 2021 
Tabla 1

Análisis cuantitativo de variación poblacional, expansión urbana y urbanizaciones cerradas

\begin{tabular}{|c|c|c|c|c|c|c|c|}
\hline Años & $\begin{array}{c}\text { Población } \\
\text { GC }\end{array}$ & $\begin{array}{l}\text { Variación } r \text {. } \\
\text { de población }\end{array}$ & $\begin{array}{l}\text { Mancha urbana } \\
\text { Total [MU] GC } \\
\text { (Aprox. km2) }\end{array}$ & $\begin{array}{l}\text { Crecimiento } \\
\text { neto mancha } \\
\text { urbana }\left(\mathbf{k m}^{2}\right)\end{array}$ & $\begin{array}{c}\text { Expansión } \\
\text { de mancha } \\
\text { urbana }\end{array}$ & $\begin{array}{l}\text { Nuevas ur- } \\
\text { banizaciones } \\
\text { cerradas [UC] } \\
\text { (Área km²) }\end{array}$ & $\begin{array}{l}\% \mathrm{UC} / \text { creci- } \\
\text { miento man- } \\
\text { cha urbana }\end{array}$ \\
\hline 1999 & 272622 & - & 48,44 (1) & - & - & - & - \\
\hline 2010 & 331195 & $21,40 \%$ & $63,56(1)$ & 15.12 & $31,20 \%$ & 0,89 & $5,85 \%$ \\
\hline 2021 & 414927 (a) & $25,28 \%$ & $92,06(2)$ & 28,5 & $44,80 \%$ & 9,77 & $34,28 \%$ \\
\hline
\end{tabular}

GC = Gran Corrientes (localidades Capital, Riachuelo y Santa Ana). (a)=Proyección INDEC para Dpto. Capital. (1)= Estimación realizada a partir de Atlas ID y fotointerpretación de imágenes satelitales históricas. (2)= Estimación mediante fotointerpretación

Fuente: elaboración propia, 2021

\section{Disparidades extremas y nuevas mecánicas de despojo}

Como se intentó exponer en el anterior apartado, la máquina de exclusión o de destrucción innovadora no es algo reciente; sin embargo, adquiere nuevas temporalidades, sujetos y mandatos en las políticas urbanas. Autores como los referenciados al principio llaman a construir una contrahegemonía en los discursos sobre el devenir urbano, cuando el proceso de marginalización de la vida de muchas personas y la destrucción de bienes ambientales comunes avanzan de manera convulsiva. El urbanismo neoliberal produce la conformación de enclaves de disparidad extrema: acumulación de dificultades para sobrevivir, por un lado; riqueza, suntuosidad, exaltación elitista por el otro; espacialmente lejos o cerca, concebidos como realidades desconectadas entre sí. En relación con esto, se gobierna estratégicamente garantizando la acción del mercado, en conjunto con biopolíticas que sostienen la pobreza a niveles aceptables o invisibles para el centro.

RoLnik (2017) lo manifiesta exponiendo que la planificación urbana y las regulaciones que de ella derivan suscriben y actúan sobre la base de un modelo de ciudad ideal: 
calculando su éxito en $\mathrm{m}^{2}$ construidos sin importar si los espacios son realmente habitados. Las gestiones locales se constituyen en facilitadoras de las necesidades de inversores inmobiliarios, quienes construyen para los sectores de mayor solvencia. Así lo afirma una funcionaria de la Secretaría de Desarrollo Urbano, quien expresó que "dentro de la Municipalidad trabajamos en incorporar nuevas ordenanzas (...), de comprender el ecosistema profesional y dar respuesta al ámbito privado que es realmente el que hace ciudad"13.

\section{Naturaleza privatizada por sociedades anónimas}

Con diferencias y similitudes respecto de las estudiadas urbanizaciones cerradas náuticas del delta o de la Región Metropolitana de Buenos Aires (Pintos, 2017, 2020; Svampa \& Viale, 2014), en nuestros territorios se ha avanzado desde principios de siglo en la ocupación de áreas del agua mediante loteos de tipo abierto, urbanizaciones cerradas (UC) o "clubes de campo" (CC) (mapas 3 y 4). Alrededor de un 34,28 \% de la expansión urbana y ocupación de suelo rural producida entre 2010-2020 corresponde a barrios privados que se localizan entre las localidades del área metropolitana de Corrientes (Capital, Santa Ana, Riachuelo) (tabla 1). Desde principios de siglo se avanza en silenciosas transformaciones (PugliEsE, 2009; en Pintos \& Narodowski, 2012) a partir de la concepción de nuevos productos inmobiliarios que imitan pautas globales. En su gran mayoría, el consumo y selección de estos corresponde a segmentos de clase media y media alta, promovidos como paraísos donde vivir e invertir bajo retóricas múltiples. Es lo que Pintos (2020) denomina un submercado del suelo que genera una oferta mediante "una suerte de nueva ruralidad urbanizada" (p. 29), que combina recursos o imágenes de una naturaleza prístina y afable junto con ammenities de lujo (salones, piscinas, canchas de tenis) y seguridad (cierre con cercos eléctricos, guardias las veinticuatro horas).

Es relevante resaltar que el territorio de lagunas y los bordes ribereños del área metropolitana resultan idílicos para los desarrolladores, ya que, a diferencia de las urbanizaciones del Delta, no requieren monumentales obras de ingeniería hidráulica y movimiento de tierra para producir lagos artificiales y aumentar las vistas al agua. Sin embargo, la avanzada mediante tala, construcción de vialidades, alteo de terrenos tiene un impacto ambiental evidente y para nada regulado. Se pueden contabilizar alrededor de 29 BP o CC (en diferentes etapas de preventa, urbanización y ocupación) que se localizan en torno de la reserva
13. Charla virtual "Incidencia de los arquitectos en la construcción de ciudades del Nordeste Argentino", organizada por la Secretaría de Posgrado FAU-UNNE. 
14. La reserva de Laguna Brava posee alrededor de cinco desarrollos: Laguna Brava Park, Rincón de Laguna, Laguna Brava, Los Quebrachos y los desarrollos Santa Lucía I, II y III, que realizaron canalizaciones ilegales en el área.

15. Allí se localiza el club de campo Dos Lunas, que es un emprendimiento de la familia

De la Vega y asociados mediante dos sociedades anónimas: Las Dos Lunas SA, 1 y 2. Se encuentran Buffalo Country Club y los clubes de campo Buena Vista, Laguna Sur y Barrio Nuevo.

16. En la localidad de Riachuelo son Catalinas Country Club y el emprendimiento Arenas del Riachuelo.

17. Se distinguen los localizados en la RP 43, como Golf Club, Solar de los Guácaras, Don Manuel, Che Gente Cuera, Los Azahares, Aranduroga Country Club,

Los Frutales, Arandú; y en la localidad de Santa Ana los clubes de campo Lomas de Santa Ana, Carlos Márquez, Pinar del Sol.

18. El más avanzado es el emprendimiento Marinas del Taragüí. de Laguna Brava ${ }^{14}$ (Ruta Provincial 5); en calle 48 (la cual conecta transversalmente la ruta provincial 5 con la 43) ${ }^{15}$; ruta provincial 43 hacia Santa Ana ${ }^{16}$; en Riachuelo ${ }^{17}$ y en la costa norte $^{18}$. Todos absorben y cercan en sus loteos lagunas, esteros, costas del río, pero en áreas relativamente altas (mapas 2 y 4 ).

La mayoría de estos barrios se localizan hacia el interior del territorio en "lagunas de lomadas arenosas", constituidos por "lagos someros" y humedales interconectados y con alta fluctuación en sus niveles de agua (CONTRERAs \& OJEDA, 2018). Estos son rellenados o intervenidos incluso hasta su desaparición. Lo mismo ocurre con aquellos localizados en la costa, que contribuyen a la polderización de áreas inundables, la construcción de canales artificiales, la destrucción de bosques ribereños. De esta manera se avanza en el acaparamiento y privatización de bienes comunes donde el paisaje pasa a ser una excusa, una estrategia de mercado que "desprecia las valoraciones posibles del paisaje real y sus significados pretéritos” (Pintos, 2017, p. 25). Se destruye su valor colectivo en términos ecosistémicos y sus servicios ambientales como mitigadores de las inundaciones.

Los emprendimientos se constituyen mediante sociedades anónimas o en la forma de consorcios de propiedad horizontal, donde confluyen tanto inversores como quienes buscan habitar o construir segundas residencias. En algunos de estos emprendimientos se recurre a un discurso propagandístico de la generosidad de hacerlo accesible a partir de su oferta al resto de la ciudad. Así uno de los impulsores del Club de Campo Dos Lunas menciona que este "brinda la posibilidad de acceder a toda la Sociedad Correntina y de Resistencia a un lugar como es este para vivir o pasar un buen fin de semana (...) un lugar que está al servicio de la comunidad” (Consultora Publicitaria, agosto de 2018). Se trata, como dice Foucault (2007) recurriendo a Ropke, de la idealización de comunidades naturales, donde se consolidan valores conservadores de la familia y los vecindarios: una biopolítica que se plantea como un retorno a la naturaleza, pero que debe ser leído como mercantilización, multiplicación de formato empresa y el despliegue de todo tipo de artefactos de encierro y seguridad para la autosegregación.

Asimismo, desde el Estado los funcionarios locales conciben normativas a medida, como es la Ordenanza 2034, que adhiere a la ley provincial N. ${ }^{\circ} 5405$ estableciendo los requisitos 
básicos para clubes de campo. La Ordenanza 5202/2009 los habilita en las llamadas "Zonas de Interés Paisajístico" con posibilidades de edificar viviendas unifamiliares en parcelas mayores a $750 \mathrm{~m}^{2}$. Esto implica la posibilidad de despliegue territorial en menor densidad, en un área anteriormente rural, lo cual supone un salto diferencial de renta importante que multiplica exponencialmente la ganancia del grupo desarrollador y accionistas. Por otra parte, el Instituto Correntino del Agua y el Ambiente (ICAA), autoridad reguladora en materia ambiental, practica una mecánica de permisivismo (sin producir normativas de ordenamiento del territorio en función del riesgo hídrico, sin actuar de oficio ni exigir estudios confiables de impacto ambiental) ${ }^{19}$.

Poco se contempla su impacto en las inundaciones en áreas más bajas de la cuenca. A partir de las lluvias extremas concentradas en días de 2016 y 2017, se produjeron inundaciones $^{20}$ en áreas como La Olla o barrios Ponce, Cremonte, Bejarano, Laguna Soto, Laguna Brava (OJEDA, 2019). El Ejecutivo municipal dispuso la Resolución 1696 en agosto de 2017, en la cual se suspendía la aprobación de urbanizaciones "hasta contar con el plan Hídrico Integral de todo el territorio municipal a elaborar por el ICAA". Inmediatamente el organismo llamado a accionar repuso que "no es necesario suspender nuevas habilitaciones" (ICAA, 13 de agosto 2017). En las imágenes 5 se pueden observar comparativamente a partir de fotografías tomadas por un drone de la Municipalidad (durante las inundaciones del 2017) barrios privados bordeados por el agua en los límites entre Capital y Santa Ana y barrios como Laguna Brava, al sur, totalmente anegados (El Litoral, 28 de abril de 2017).

Por otra parte, el actual gobierno municipal prometió en su campaña electoral un "Plan Hídrico", que consiste en la limpieza y reparación de sumideros o la construcción de nuevos ductos (MC, s/f). Aún queda por indagar en este proceso; sin embargo, las lluvias en el verano de 2019 mostraron inundaciones análogas a las de 2016. Mientras este tipo de urbanizaciones avanzan sin acompañarse de estudios ambientales ni normativas locales que regulen los usos en función del riesgo, se recurre a retóricas del cambio climático y falta de planificación (siempre atribuidas a gestiones anteriores). A su vez, queda por indagar en las diferencias entre estos productos, entre espacios de exclusividad y loteos destinados a sectores de ingresos medios, partiendo de la siguiente pregunta: ¿en qué medida estos productos exclusivos son una demanda real para habitar, segundas residencias o un producto especulativo?
19. Casos representativos son los barrios privados como Santa Lucía I, II y III, que lotearon, rellenaron, desmontaron y produjeron canalizaciones artificiales de alto impacto en la reserva de Laguna Brava (República de Corrientes, 25 de septiembre de 2020).

20. OJEDA (2019) registra el colapso de cañerías de infraestructuras o de arroyos entubados como el Limita, interrupción del servicio de energía eléctrica o de transporte, viviendas afectadas y deterioradas, agua hasta el pecho de los habitantes en la Olla (p. 24). 

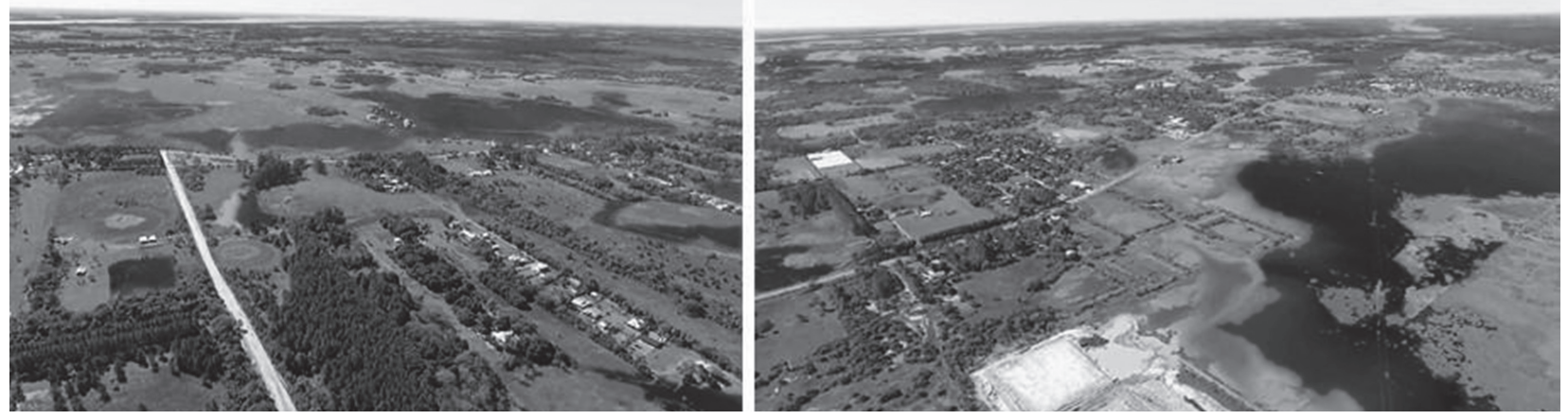

Imagen 5. (Izq.). Territorio de Avance Clubes de Campo al norte de Ruta 5. (Der.) Anegamiento de barrios sobre Ruta 5. Fuente: El litoral, 28 de abril de 2017

21. Estimación sobre la base del Registro Nacional Barrios Populares (2019). Se reconoce que se trata de una aproximación, aunque esta ha sido cuestionada por presentar un conteo acotado, y es posible que el número de asentamientos sea mayor al definido por el registro.

\section{La costa: barrios populares para habitar o suelo para el mercado}

El nicho de mercado anteriormente expuesto se propone como oportunidad para un sector solvente; sin embargo, el avance indiscriminado sobre áreas de gran valor ecosistémico, como los humedales, también se constituye en oferta para los sectores medios que demandan suelo urbanizado para habitar en períodos de subsidios a la demanda, como es el caso del ProCreAr. Esto alienta la producción de urbanizaciones con déficits de infraestructura básica y llamando a habitar cada vez más lejos de la ciudad.

No obstante, si se piensa en las formas de producción social o autogestionaria del hábitat en la ciudad, se vuelve la mirada principalmente a los 63 barrios populares existentes y en diferentes condiciones de criticidad. En estos habitan alrededor de 60.000 personas (el $19 \%$ de la población total ${ }^{21}$ ), de los cuales el $40 \%$ son barrios históricos, que surgen entre los 60 y 80 y un $60 \%$ a partir de los años 90 . A su vez, veinticinco se localizan en la costa: doce en el bañado norte; trece en el bañado sur.

El barrio Esperanza está emplazado en la costa del río Riachuelo y siete barrios se ubican en un área baja conocida como "La Olla". Como se expuso anteriormente, son lugares frecuentemente afectados durante las inundaciones o anegamientos, pero con áreas internas de mayor criticidad, con altos niveles de vulnerabilidad ambiental y hacinamiento de hogar o intralote. Este es el caso del Sol de Mayo y Quinta Ferré, divididos por el arroyo Santo 
Domingo, el cual fue densamente ocupado en su valle de inundación. Se trata de un foco de contaminación y de riesgo por el aumento de los caudales pluviales conducidos hacia el río (imagen 6) y que permanece invisibilizado para la agenda pública, a pesar de los reclamos de la Red Vecinal Zona Norte. Las intervenciones estatales en el área han sido en los últimos años insignificantes y deficientes: enripiado de alguna vía principal, limpieza superficial del arroyo, colocación de postes o construcción de un número reducido de viviendas.

Mientras tanto, desde las secretarías municipales impulsan normativas que conceden mayor capacidad constructiva en el área central. Estas salen como pan caliente del Concejo Deliberante local, lo que evidencia acuerdos con la Cámara de Desarrolladores Inmobiliarios, sin estimar las capacidades de la infraestructura existente y sin captación de plusvalías urbanas (Olmedo \& Rus, 2020). La trampa radica en esgrimir que esto implica mayor densificación y compacidad urbana para resolver el déficit habitacional, cuando no resulta para nada garantizado frente al impacto que esto genera en los valores del $\mathrm{m}^{2} \mathrm{o}$ de alquileres que se disparan (JARAmillo, 2008). De esta mecánica de exclusión, garantizada por la propiedad privada en el capitalismo, se desprende la existencia de un mercado informal y las tomas de tierra. Quienes ocupan terrenos ociosos para habitar son sometidos formas de criminalización, con o sin acompañamiento judicial, mediante amenazas o consumación de desalojos. Algunas organizaciones como el Observatorio de Conflictos Sociales del NEA denunciaron cinco desalojos en 2018 (Momarandú, 6 de noviembre de 2018). Durante 2020, en plena crisis sanitaria de la COVID-19, se intentó desalojar a 60 familias del Barrio Quilmes, se expulsó violentamente a familias del Barrio Esperanza y se amenaza constantemente a familias en las tierras municipales de Santa Catalina (Turba-Colectivo de Hábitat, junio de 2020).

Las dificultades de accesibilidad al suelo urbano se constituyen en un aspecto central de la ciudad latinoamericana contemporánea, donde un gran porcentaje de habitantes no cumplen las expectativas jurídicas de propiedad escriturada y se alejan de la aspiración de una vivienda propia. La autogestión y autoconstrucción son las soluciones implementadas por sectores populares; sin embargo, los esfuerzos de los pobres son poco acompañados desde la agenda local. De manera contraria, cuando las áreas ribereñas se vuelven interesantes para el mercado (por inversión estatal o normativas que incrementen la capacidad constructiva), los agentes estatales facilitan excepciones y reconocen derechos de propiedad a particulares. RoLNIK (2017) manifiesta que el aparato de planificación y la vara de legalidad estatal pueden declarar la suspensión de cierto orden y definir aquello que es "legal e "ilegal". 


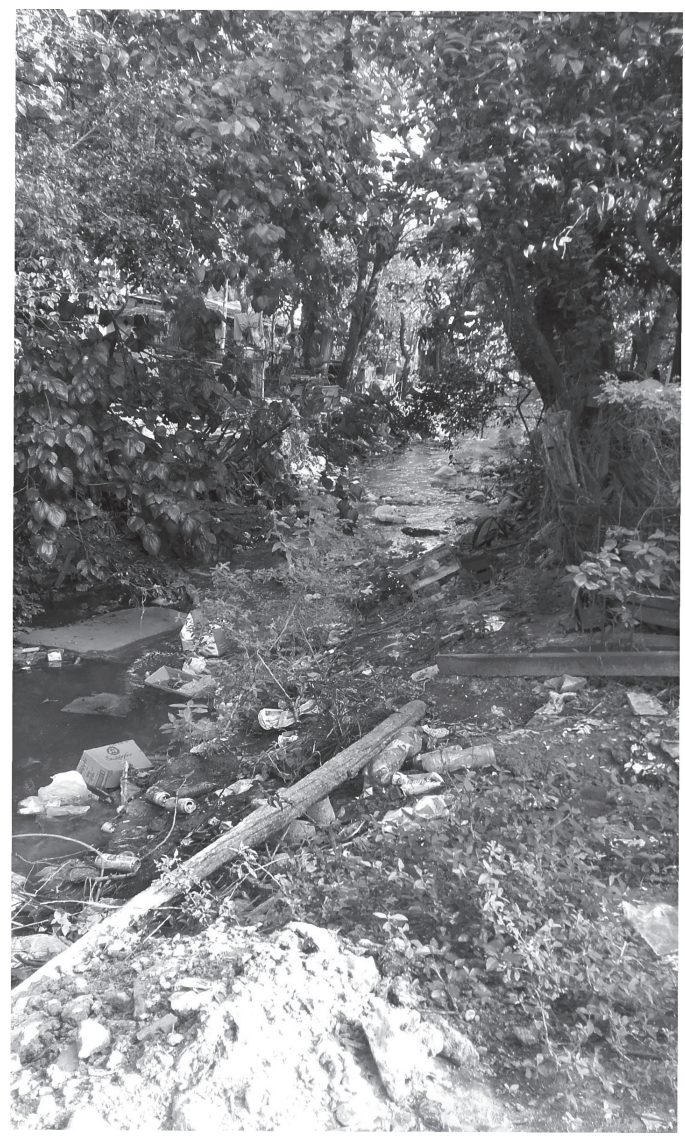

Imagen 6. Arroyo Santo Domingo.

Autoría propia, 2017
En ese sentido, se articulan los llamados procesos de "acumulación por desposesión” (Harvey, 2004; cit. en Svampa \& ViaLE, 2014, p. 284) y de unlock land values (Rolnik, 2017), en que se abren las puertas para el ingreso de capitales y el moldeamiento de áreas a su conformidad. En Corrientes, esto puede verse a través de la concepción de grandes proyectos urbanos de defensas y paseos ribereños, como el caso de la Costanera Juan Pablo II (1998-2008), construidos mediante préstamos internacionales del Banco Mundial y un largo trecho de esfuerzo e inversión pública. Si bien estos generan espacios públicos de enorme calidad y uso, se acompañan por un invisibilizado proceso de desplazamiento forzado o inducido de los pobres, y la proliferación de emprendimientos inmobiliarios de alta gama y de gran impacto (Rus, 2019a; Rus, 2019b). Resulta ejemplificadora la sanción desde el Concejo deliberante local de una excepción para la edificación de un paseo de compras en la playa pública Arazaty (Ordenanza 6832/2019). A su vez, durante muchos años se presenció el relleno paulatino y alevosamente acelerado durante la pandemia para la construcción de un terraplén ilegal por parte de la empresa Bienes Raíces SA sobre el lecho del río para edificar torres en alturas (NuEva Mirada, 3 de septiembre de 2020). 
Todo lo anterior va en consonancia con la promoción desde la Agencia de Administración de Bienes del Estado (AABE) - ente nacional-, junto al Municipio y varias entidades locales, de la subasta de tierras públicas extremadamente valiosas para la ciudad y a precios viles (Plan Costero), con la desafectación y el aumento exponencial de la edificabilidad mediante la Ordenanza 6635/2018 (Olmedo \& Rus, 2020).

Por otro lado, nada de esto ha ocurrido sin el surgimiento de numerosas formas de resistencia que visibilizan el desacuerdo empujando discursos combativos desde la defensa de lo público, la justicia social, la redistribución de reconocimiento y recursos. Este es el caso del colectivo Defensores de los Espacios Públicos Costeros, quienes desde 2018 han llevado adelante procesos judiciales y actividades ciudadanas para frenar estos procesos.

\section{Algunas reflexiones}

Las transformaciones urbanas promovidas entre mediados y fines del siglo XX en Corrientes se sostuvieron a partir de un Estado inversor, productor de mejoras basadas en los preceptos colonizadores de la modernización y que permitía gradualmente el avance del capital hacia ciertas áreas, mientras que subsidiaba o destinaba presupuesto a cuentagotas en los barrios populares que crecían exponencialmente a partir de los años 50. Sin embargo, hoy se despliegan nuevas políticas que introducen cambios extensivos y urgidos. Estas aceleran la producción de reductos cooptados por las clases altas (Pintos \& NARodowskY, 2012), tanto en áreas centrales cualificadas como en las periferias metropolitanas, donde se consume suelo indiscriminadamente y se devora suelo de humedales. Vemos en Corrientes avanzar hacia una ciudad rentista, especulativa e insostenible, donde el suelo se incrementa a niveles inaccesibles para las mayorías y la ocupación informal crece en áreas de numerosos déficits y criticidades.

En este trabajo se buscó proponer una lectura contemporánea, enraizada en la memoria del pasado de esta ciudad latinoamericana periférica e introduciendo el despliegue de procesos neoliberales aún en indagación. Se resaltó, a su vez, que, si bien estos procesos suelen ser comprendidos como casos disociados, no pueden desvincularse del carácter netamente político, relacional y material de las formas de planificación encaradas. Por lo tanto, es fundamental desechar la romántica interpretación que presenta al Estado como ente abstracto que "no planifica", "no posee los suficientes recursos". Se propone romper con la retórica 
de la escasez, que respalda la participación privilegiada de actores del mercado, y seguir el arbitraje que reproduce un tipo particular de reparto, haciendo una crítica de la agenda política territorial y sus prioridades. Cabe también someter nuestros estudios a revelar el "detrás" de las llamadas operaciones estratégicas que promulgan precozmente el desarrollo o progreso con efectos beneficiosos para todos, como es el caso de un shopping en la playa pública. Los autores citados abordan casos análogos en nuestro país y permiten comprender esta agenda local en el marco estructural del neoliberalismo, un proyecto colonizador que ve surgir patrones coincidentes, pero con impactos, formas de resistencia y distanciamientos para profundizar desde cada lugar.

Por otra parte, tal y como ContreRAS y OJEDA (2018) lo exponen, se continúa creando la sensación de novedad ante inundaciones, tomas de tierra, desastres ambientales, compensada por el sentido común que promulga el individualismo de los privilegiados y el desprecio de los pobres. Presenciamos cómo se constituyen acuerdos más o menos formalizados que fabrican excepciones, normativas, discursos al servicio del capital, acompañados por la permisividad, el destrabe de tierras para proyectos exclusivos y la omisión total de exigencias en contrapartida (por ejemplo, la recuperación de plusvalías urbanas). Son políticas unidireccionales, porque contemplan como protagonistas a grupos selectivos, y desinteresadas, porque desconocen u omiten la realidad social y las otras voces.

Es así que el agua como agente constitutivo del territorio se mueve entre áreas de exclusividad y de exclusión y debe adaptarse a transformaciones con efectos ambientales difíciles de enmendar y cuyos costos son diferencialmente repartidos entre grupos sociales. Ante este panorama nada tranquilizador, debemos construir una crítica que se valga de la memoria de los conflictos, para luego sembrar otras formas de planificación que reivindiquen las formas colectivas e innovadoras de producción social del hábitat y del ejercicio cotidiano del derecho a la ciudad.

\section{Referencias bibliográficas}

Aalbers, M. B. (2013). Neoliberalism is dead... long live neoliberalism! International Journal of Urban and Regional Research, 37(3), 1083-1090.

Alberto, J. A.; Arce, G. A.; Mignone, A. M. \& López, S. (2018). Dinámica y tendencia de la expansión urbana del Gran Corrientes y su área de influencia directa. Revista Geográfica Digital. 15 (30). 
Alcalá, L. \& Rus, F. (2017). Áreas Urbanas Deficitarias Críticas en Territorios con Riesgo Hídrico. Análisis comparado de situaciones en las ciudades de Resistencia y Corrientes. VI Seminario Internacional de Ordenamiento Territorial. La nueva agenda territorial: innovación, planificación y gestión. Mendoza, Argentina.

Botticelli, S. (2017). La impronta neoliberal en el new public management: gobernar a través del mercado. Trabajo y sociedad: Indagaciones sobre el empleo, la cultura y las prácticas políticas en sociedades segmentadas, (29), pp. 677-693.

Brenner, N.; Nik, T. \& Peck, J. (2009). Urbanismo neoliberal: la ciudad y el imperio de los mercados. Temas Sociales, Vol. 66, pp. 1-11.

Contreras, F. I. \& Ojeda, Elsie A. (2018). Consecuencias de la expansión urbana sobre el paisaje de lagunas de lomadas arenosas (Corrientes, Argentina). En: E. M. Abraham; R. D. Quintana y G. Mataloni (Eds.), Aguas + Humedales (pp. 363-369). Primera ed. Universidad Nacional de San Martín (UNSAM Edita).

Foschiatti, A. \& Bolsi, A. (1993). La población de la Ciudad de Corrientes entre 1588 y 1988. Análisis desde la Perspectiva Geográfica. Revista Geográfica, 118, pp. 65-116.

Foucault, M. (2007). Nacimiento de la Biopolítica. Curso en el Collège de France (1978-1979). Fondo de Cultura Económica.

Gutiérrez, R. \& Sánchez Negrette, Á. (1988). Evolución urbana y arquitectónica de Corrientes. Volúmenes 1-2. Instituto Argentino de Investigaciones de Historia en la Arquitectura y el Urbanismo.

Harvey, D. (2008). El neoliberalismo como destrucción creativa. Revista Apuntes del CENES, 27, (45).

Jaramillo, S. (2008) Hacia una teoría de la renta del suelo urbano. Ed. Uniandes.

Martín, F. \& Larsimont, R. (2016). Agua, poder y desigualdad socioespacial. Un nuevo ciclo hidrosocial en Mendoza, Argentina (1990-2015). En: Merlinsky, G. (Comp.) Cartografías del conflicto ambiental en Argentina 2 (pp. 31-53). Ciccus Ed.

Minadeo, M. (1988). Las calles de Corrientes. En el IV centenario de su fundación. 1588-1988. Recuperado de: Archivo General de la Provincia de Corrientes.

Mudge, S. L. (2008). What is neo-liberalism? Socio-economic review, 6(4), pp. 703-731.

Municipalidad de Corrientes (2014). Máster Plan Santa Catalina - Corrientes 2014-2034. Tomo I: Diagnóstico. Corrientes: Fideicomiso Santa Catalina.

Ojeda, E. (2019). El anegamiento a través de la prensa: El caso de la ciudad de Corrientes. Boletín geográfico, 41(2), 13-36. 
Olmedo, R. \& Rus, F. (2020). Entre gallos y medianoche. Legislaciones urbanas recientes en las ciudades de Corrientes y Resistencia, Argentina. Pensum 6(6), pp. 84-98.

Pintos, P. \& Narodowsky, P. (Coord.) (2012). La privatopía sacrílega. Efectos del urbanismo privado en humedales de la cuenca baja del río Luján. Imago Mundi.

Pintos, P. (2017). Extractivismo inmobiliario y vulneración de bienes comunes en la cuenca baja del río Luján. En Vásquez, A. M. (Comp.), Extractivismo urbano. Debates para una construcción colectiva de las ciudades (pp. 23-39). Fundación Rosa Luxemburgo.

Pintos, P. (2020). Humedales en disputa a las puertas de Buenos Aires. Comunes urbanos, espacialidades injustas y conflictos. En Merlinsky, G. (Coord.) Cartografías del conflicto ambiental en Argentina 3 (pp. 29-54). Ed. Ciccus, Clacso.

Reygadas, L. (2019). Entre Marx y Latour: Cristalización espacial de las asimetrías, agencia del territorio y desigualdad. En: Di Virgilio, M. M. y Perelman, M. (Comp.), Disputas por el espacio urbano: Desigualdades persistentes y territorialidades emergentes (pp. 19-41). Buenos Aires: Biblos.

Rodríguez, M. F. \& Socoloff, I. (2017). El acceso a la vivienda: un desafío pendiente en la agenda estatal. En: Junio, C. (Comp.) Derechos sitiados Redefiniciones de lo público en la Ciudad de Buenos Aires (pp. 27-46). Ed. CCC.

Rolnik, R. (2017). La guerra de los lugares. La colonización de la tierra y la vivienda en la era de las finanzas. LOM Editores.

Rose, N. (1997). El gobierno en las democracias liberales "avanzadas": del liberalismo al neoliberalismo. Archipiélago: Cuadernos de crítica de la cultura (29), pp. 25-40.

Rus, F. (2019a). El proceso de reestructuración de la costanera sur de Corrientes, Argentina: una genealogía de apropiaciones, expulsiones y resistencias. Revista $A D$ Nea (7), pp. 107-120.

Rus, F. (2019b). Al frente, al margen. La transformación de la frontera socio-urbana en las áreas costeras de la ciudad de Corrientes, Argentina Tesis de maestría. Maestría en Urbanismo de la Universidad Nacional de Córdoba, Argentina. https://rdu.unc.edu.ar/handle/11086/17751

Smith, N. (2005). El redimensionamiento de las ciudades: la globalización y el urbanismo neoliberal. En: Harvey, D. y Smith, N. Capital financiero, propiedad inmobiliaria y cultura. (pp. 59-75). Ed. Universitat Autonoma de Barcelona. 
Snaider, P. \& Ramírez, L. (2018). Alturas de las aguas en épocas de creciente y estiaje. El Ojo del Cóndor 9, pp.16-19. Instituto Geográfico Nacional.

Socoloff, I.; Camji, N.; Montagna, F.; Peralta, A. \& Sahakian, Y. L. (2020). Estrategias de disposición del suelo público: mercantilización e inflexiones del neoliberalismo urbano en Ciudad de Buenos Aires (2015-2018). Territorios, (43), $1-24$.

Svampa, M. \& Viale, E. (2014). Maldesarrollo. La Argentina del extractivismo y el despojo. Ed. Katz.

Vásquez Duplat, A. M. (2017) (Comp.). Extractivismo urbano: debates para una construcción colectiva de las ciudades. Ed. Fundación Rosa Luxemburgo.

\section{Otras fuentes}

Consultora Publicitaria (14 de agosto 2018). Programa especial: Club de Campo “Dos Lunas”. https://www.youtube.com/watch?v=hq-UQ0MHUHw\&t=916s

Diario El Litoral (28 de abril de 2017). La Municipalidad realizó un informe especial sobre las inundaciones en Capital. https://www.ellitoral.com.ar/corrientes/20174-28-13-26-0-la-municipalidad-realizo-un-informe-especial-sobre-lasinundaciones-en-capital

Instituto Correntino del Agua y el Ambiente (13 de agosto de 2017). Barrios privados: No es necesario suspender nuevas habilitaciones. http://icaa.gov.ar/barriosprivados-no-necesario-suspender-nuevas-habilitaciones/

Ley de presupuestos mínimos de protección ambiental para el uso racional y sostenible de los humedales, Proyecto de Ley Unificado, Equipo técnico de la Comisión de Recursos Naturales y Ambiente Humano de la Honorable Cámara de Diputados de la Nación, noviembre de 2020.

Momarandú (6 de noviembre de 2018). Alertan sobre el aumento de desalojos violentos en Corrientes. http://www.momarandu.com/amanoticias.php $? \mathrm{a}=7 \& \mathrm{~b}=0 \& \mathrm{c}=169480 \& \mathrm{fbclid}=$ IwAR3LkC-UBRlzCCHKLkjBTP7ueq30vL0wRYKAeJigxvV5SR6iev9liAH1ZA

Municipalidad de Corrientes. Plan Hídrico. (Fecha de consulta: 15 de diciembre de 2020) https://ciudaddecorrientes.gov.ar/plan-h-drico

Ordenanza N. ${ }^{\circ}$ 5202/2009. http://www.sgpc.concejocorrientes.gob.ar/web/norma/documentos/ dfd9c3d851c563a57c87623e44b9d5b3.pdf 
República de Corrientes (25 de septiembre de 2020). Preocupación vecinal por obras privadas de canalización en Laguna Brava. https://republicadecorrientes. com/2968-preocupacion-vecinal-por-obras-privadas-de-canalizacion-enlaguna-bravaTurba - Colectivo de Hábitat (junio de 2020). ¿Cómo se vive la pandemia COVID-19 en el Gran Resistencia y Gran Corrientes? Café de las Ciudades. https:/cafedelasciudades.com.ar/sitio/contenidos/ver/323/ como-se-vive-la-pandemia-covid-19-en-el-gran-resistencia-y-grancorrientes.html 